\title{
Este Cavalheiro era João Semana
}

\author{
This Gentleman was João Semana
}

Jorge CRUZ1,2

Acta Med Port 2014 Jan-Feb;27(1):148-150

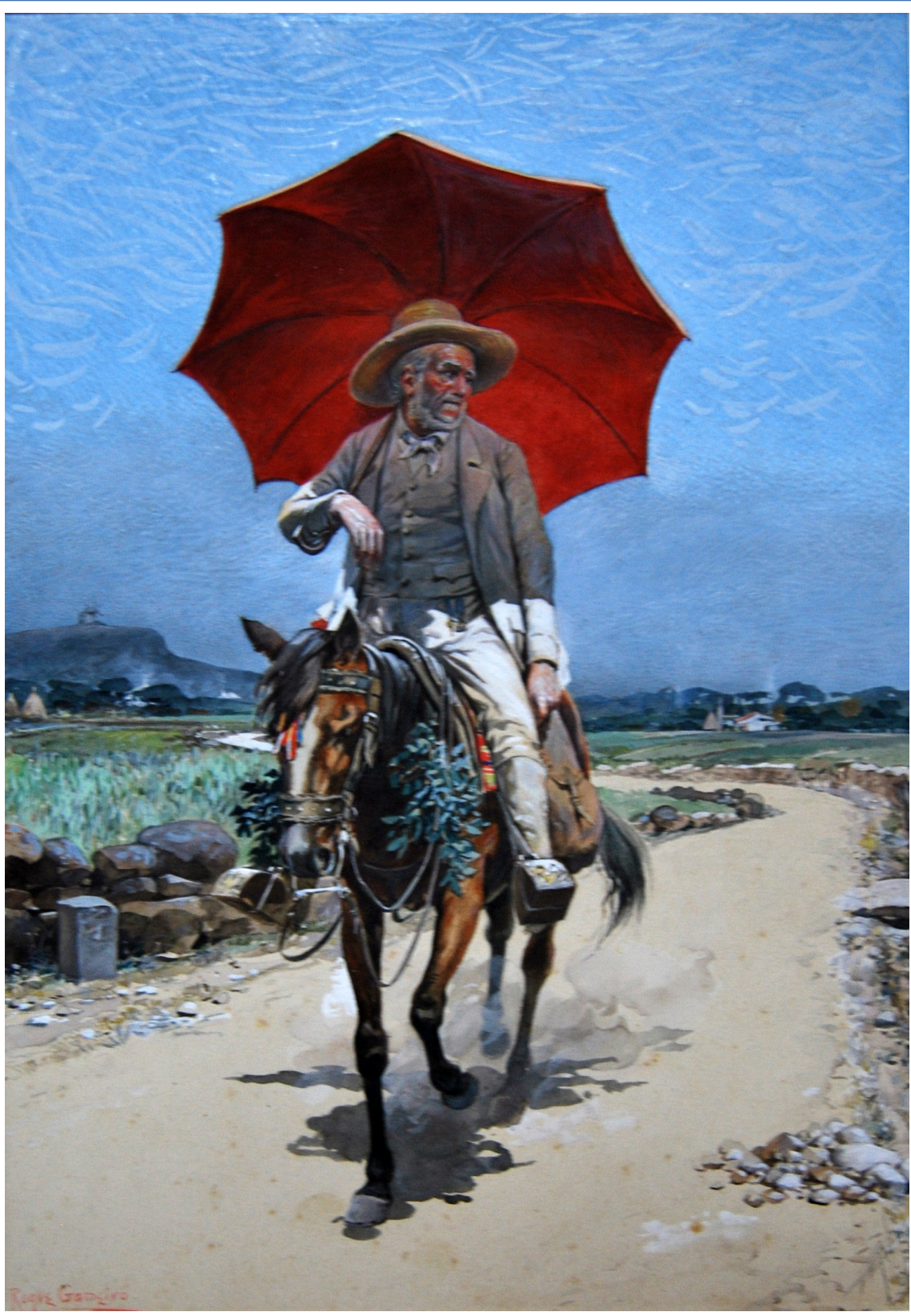

Figura 1 - "Este cavalheiro era João Semana" de Alfredo Roque Gameiro, 1904. Aguarela sobre papel 339 x 250 mm. Colecção do Centro de Arte Moderna da Fundação Calouste Gulbenkian, em depósito no Museu de Aguarela Roque Gameiro. Minde. Portugal.

Palavras-chave: História, Século XIX; Pessoas Famosas; Pintura; Literatura; Relação Médico-Doente.

Keywords: History, 19th Century; Famous Persons; Paintings; Literature; Physician-Patient Relations.

1. Médico especialista em Angiologia e Cirurgia Vascular. Doutor em Bioética. Centro Hospitalar de Entre o Douro e Vouga. Santa Maria da Feira. Portugal. 2. Instituto de Bioética. Universidade Católica Portuguesa. Porto. Portugal.

Recebido: 20 de Janeiro de 2014 - Aceite: 21 de Janeiro de 2014 | Copyright @ Ordem dos Médicos 2013 
Alfredo Roque Gameiro foi um pintor e ilustrador português, especializado na arte da aguarela. Nasceu em 1864 em Minde, no concelho de Alcanena, e faleceu em 1935 em Lisboa. Estudou na Escola de Belas-Artes de Lisboa, onde foi discípulo de Manuel de Macedo, Enrique Casanova e José Simões d'Almeida. Frequentou de 1893 a 1895 a Escola de Artes e Ofícios de Leipzig, como bolseiro do Estado português. De regresso a Portugal, assumiu a Direcção artística da Companhia Nacional Editora e posteriormente exerceu actividade docente na Escola Industrial do Príncipe Real. Considerado 'Mestre insigne da aguarela', deixou um vasto legado de obras de grande beleza e requinte, tendo obtido diversos prémios e distinções, nacionais e internacionais. ${ }^{1}$

Iniciou a sua actividade como ilustrador em 1888, pintando ao longo da sua vida inúmeras aguarelas para diversas publicações, tanto de carácter histórico e etnográfico como literárias. A maior parte do seu espólio encontra-se no Museu de Aguarela Roque Gameiro, que inclui obras do Centro de Arte Moderna da Fundação Calouste Gulbenkian, em depósito.

"Este cavalheiro era João Semana" é uma das várias aguarelas que Roque Gameiro concebeu, entre 1904 e 1905, para ilustração do romance de Júlio Dinis 'As Pupilas do Senhor Reitor'. Representa, de forma realista, a personagem João Semana, médico de aldeia, montado no seu inseparável ginete, que até meados do século $X X$ era o meio de locomoção privilegiado dos médicos que exerciam clínica no meio rural, nas frequentes visitas domiciliárias.

Júlio Dinis, pseudónimo literário de Joaquim Guilherme Gomes Coelho (1839-1871), concluiu o curso de Medicina com distinção em 1861 na Escola Médico-Cirúrgica do Porto e integrou o corpo docente desta instituição a partir de 1865. A tuberculose pulmonar de que padecia desde a juventude (teve a primeira hemoptise no $2 .^{\circ}$ ano do curso), foi responsável pela sua morte prematura aos 31 anos. A doença levou-o a procurar climas mais propícios ao repouso e convalescença. Deslocou-se algumas vezes por esse motivo à vila de Ovar, donde era natural seu pai, e ao Funchal, escrevendo algumas das suas obras durante os curtos períodos em que permaneceu nestes locais. É considerado um dos maiores romancistas da literatura portuguesa do século XIX., ${ }^{2,3}$

Egas Moniz, no seu livro notável 'Júlio Dinis e a sua obra', identificou em Ovar as gentes e os lugares que terão servido de inspiração para 'As Pupilas do Senhor Reitor', o primeiro romance publicado do escritor. Para o distinto professor, 'o João Semana das Pupilas é o retrato fiel do cirurgião João José da Silveira, que, ao tempo da estadia de Júlio Dinis em Ovar, exercia a profissão médica com grande sucesso, naquela região'. ${ }^{4}$ Segundo Egas Moniz, o Dr. Silveira 'era um clínico dedicado aos seus doentes como mais se não podia ser. Fosse a que hora fosse, em noite tempestuosa de inverno, ou à hora dos frugais repastos, estava sempre pronto a interromper o sono reparador ou a refeição principiada para acudir às chamadas dos doentes'. ${ }^{4}$
Maria José Oliveira Monteiro, em 'Júlio Dinis e o enigma da sua vida', considera que muitas figuras das obras Dinisianas correspondem a pessoas reais da povoação de Grijó, onde o escritor passou grande parte da infância, após o falecimento da sua mãe, também vítima de tuberculose. $\mathrm{Na}$ opinião da autora, o celebrado João Semana apresenta afinidades com o Dr. Joaquim Silvestre Correia da Silva, estimado pela população local pela sua personalidade alegre e divertida, bem como pelo seu carácter de benfeitor dos mais desfavorecidos. ${ }^{5}$ Nas suas palavras, 'sendo o único cirurgião formado de mais saber e fama que nesta época existia em Grijó e imediações, podia ter adquirido boa fortuna num tempo em que os médicos eram raros, porém era um mãos largas para todos, e à maior parte do povo não levava dinheiro nem avença'. ${ }^{5}$

Seja como for, o que parece seguro é que a personagem João Semana, uma das mais conhecidas e apreciadas de toda a obra do escritor, não representa um ideal utópico e irrealista, mas foi concebida a partir de clínicos reais inteiramente dedicados ao serviço dos doentes. ${ }^{6,7}$ Numa época em que o tratamento da maioria das enfermidades era muito elementar e pouco eficaz, era ainda mais pertinente o aforismo dos médicos franceses Bérard e Gubler, 'curar por vezes, aliviar muitas vezes, consolar sempre'.

João Semana reúne as virtudes da generosidade, altruísmo, beneficência e sentido de humor, essenciais na relação médico-doente ao longo da história da humanidade. Tal atitude contrasta com a de alguns clínicos, denunciada em outros clássicos da literatura, de paternalismo arrogante, avidez pelos bens materiais, competição feroz ou ambição desmesurada pelo poder e influência, que tem levado alguns profissionais a sacrificarem a nobre vocação médica no altar da fama, do lucro ou do poder. ${ }^{8-10}$

A humanização dos serviços de saúde requer que os profissionais estejam conscientes da importância fundamental de virtudes como a empatia, o cuidado, a beneficência ou o altruísmo, na relação assistencial médico-doente.

A personagem João Semana, retratada nesta aguarela, representa uma justa homenagem a todos os clínicos portugueses que, ao longo dos tempos, consideraram o serviço dedicado aos doentes a razão suprema da sua profissão.

\section{AGRADECIMENTOS}

O autor agradece ao Museu de Aguarela Roque Gameiro a gentil cedência dos direitos de reprodução deste quadro e a oportunidade de o divulgar.

\section{CONFLITOS DE INTERESSE}

O autor declara a inexistência de conflitos de interesse na realização do presente trabalho.

\section{FONTES DE FINANCIAMENTO}

Não existiram fontes externas de financiamento para a realização deste artigo. 


\section{REFERÊNCIAS}

1. Abreu ML. Roque Gameiro: O homem e a obra. Lisboa: ACD Editores; 2005.

2. Cruz L. Júlio Dinis: Biografia. Lisboa: Quetzal Editores; 2002.

3. Ricon-Ferraz A. A Real Escola e a Escola Médico-Cirúrgica do Porto: contributo para a história da Faculdade de Medicina do Porto. Porto: Edições Centenário. Universidade do Porto; 2013.

4. Moniz E. Júlio Dinis e a sua obra: com inéditos do romancista. Lisboa: Casa Ventura Abrantes; 1924

5. Monteiro MJ. Júlio Dinis e o enigma da sua vida. Porto: Edição de autor;
1958.

6. Lemos M. Gomes Coelho e os médicos. Porto: Edição de autor; 1922.

7. Antunes JL. Sobre a mão e outros ensaios. Lisboa: Gradiva; 2005.

8. Cruz J. Que médicos queremos? Uma abordagem a partir de Edmund D. Pellegrino. Coimbra: Livraria Almedina; 2012.

9. Cruz J. A morte de Ivan Ilitch: Uma leitura bioética. Rev Port Bioética 2010;10:79-92.

10. Cruz J. A relação médico-paciente em algumas obras literárias. Rev Assoc Med Bras. 2012;58:272-5. 


\section{Este Cavalheiro era João Semana}

Acta Med Port 2014:27:148-150

Publicado pela Acta Médica Portuguesa, a Revista Científica da Ordem dos Médicos

Av. Almirante Gago Coutinho, 151

1749-084 Lisboa, Portugal.

Tel: +351218428215

E-mail: submissao@actamedicaportuguesa.com

www.actamedicaportuguesa.com

ISSN:0870-399X | e-ISSN: 1646-0758

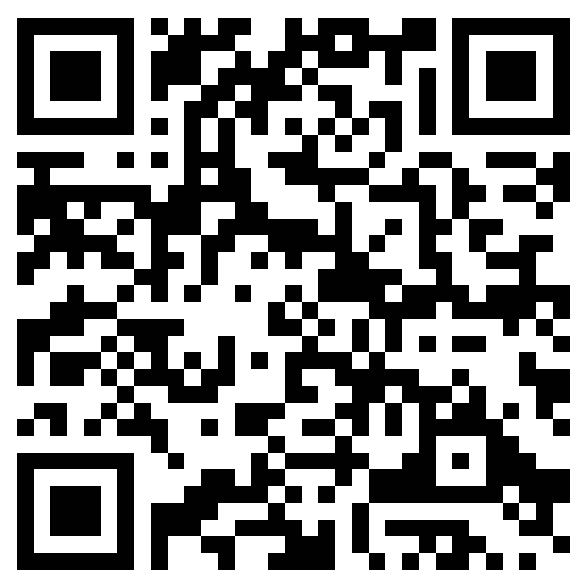

